useless unless they are prepared almost immediately before they are required, so that as a matter of fact very sensitive plates are now avoided.

Another limit to the sensitiveness which can be utilised is the diffused light proceeding from the atmosphere, either from the gas of a large town, as in Paris, or from the presence of the moon. Very sensitive plates are liable to be fogged even by diffused light in the case of very long exposures.

We have before referred to the arrangements employed for enabling the images of stars to be differentiated from any accidental spots or dots on the plate. The plate is practically exposed three times to the region of the heavens, with such a small variation of position, however, that the three images of the star on the plate appear as one to an observer who looks at it casually, and a magnifying glass is really necessary to discover the triple nature of the image. This method of working has been found to have advantages which were not anticipated in the first instance; thus, for the same total time of exposure the images of much more feeble stars are recorded with the three successive exposures than with one alone. This arises from the fact that the stars of the lower magnitudes, only being represented by very small points from $1 / 30$ to $1 / 40$ of a millimetre in diameter, would escape all observation by the naked eye, and would not be visible at all on paper copies ; while the three exposures give a larger image visible to the naked eye, and perceptible on a paper positive. Moreover, if a small planet is included in the region being photographed, the deformation of the small triangle would instantly betray its presence, even with an exposure of a quarter of an hour. Admiral Mouchez has calculated that a planet at twice the distance of Neptune would be easily recognised in three successive exposures of an hour each,- the motion of Neptune in half an hour quite destroying the triangle which it, like the stars, would make were it at rest.

The real and serious objection to the triple exposure is the wonderful patience and skill that are required to keep the instrument for three consecutive hours, without a moment's relapse, pointed rigorously towards the same spot in the sky. This is very trying work, and apt to overstrain those who perform it. Admiral Mouchez is alive to the fact that the way to obviate this difficulty is to increase the aperture of the object-glass, and this is what probably will be done before very long.

Some very interesting information is given regarding the microscopical appearances of the images of the stars seen on the negatives:- "The microscopical study of the clichés presents, moreover, much interest from many points of view, and the appearances of the images of the stars is so characteristic that it is impossible to confound them with accidental spots, as has been generally supposed; were this point of view alone regarded, it would perhaps be useless to multiply the exposures of the same plate. The stars appear on the plate, in fact, not under the simple form of a round spot of uniform black tint diminishing and becoming clearer as the star gets smaller, but as a mass of small, round, black points, very close together towards the centre for stars of the ten or twelve larger magnitudes, and more and more sprinkled, still retaining their blackness, for the fainter stars ; and at the extreme limit beyond those stars which give a definite and certain image, there still appear on the cliché some small groups of little points scattered sparsely, but evidently recording still fainter stars, the existence of which can only be suspected without any means of further confirmation.

"Unfortunately, whatever progress we may make in optics or in photography whatever, penetrating and sensitive power we may hope to give to our instruments, it is evident that we shall never succeed in seeing the most distant stars, and that at whatever limit we may arrive, there will always be beyond it an infinity of others lost in the profundity of the heavens which will always escape our knowledge, but it is by photography and the scientific study of negatives that we shall be able to go further than by any other means. From a chemical point of view also the microscopical examination of the stellar images will not be without interest, because it will help us to understand how the light acts upon the molecules of the insoluble salts of silver which are contained in the stratum of organic material which forms the sensitised plate. It is not, as I have already stated, in giving a uniform tint, more or less decided, according to the magnitude of the star, over the whole image, but really in decomposing a greater or less number of particles of salts of silver over this area, that the light works; so that we can define the image of a very feeble star as a resolvable nebula, and the others as insolvable nebulæ surrounded by a resolvable portion. I have never seen around any of these images the rings referred to by several astronomers, which have the appearance of diffraction rings seen in telescopes

"To establish the relationship between the scales of the optic and photographic magnitude of the stars, Bond has made a series of interesting experiments by varying the time of exposure and the aperture of the object-glass. These experiments have led him to an interesting result on the mode of action of light. He has found that a certain time elapsed before the action manifested itself at all, and then that it did so suddenly, ten or a dozen molecules of salts of silver in each superficial second of arc were attacked by the light; after this the number increased very rapidly according to the time of exposure. This mode of action seemed to him obscure and difficult to explain. But it seems to follow from these facts, and from the examination of our clichés, that in the manufacture of the bromide of silver, and the preparation of sensitive plates, it is of the highest importance to obtain the finest possible pulverisation of the salt."

As there is to be a Conference of Astronomers at Paris next Easter to discuss the whole question of astronomical photography, it is well that Admiral Mouchez and his staff are accumulating so many facts to help in the discussion.

METEOROLOGICAL CONDITIONS AT THE TIME OF THE ERUPTION OF MOUNT TARA WERA, NEW ZEALAND

$\mathrm{I}$ the Government Sanatorium at Rotorua there is a self-registering barometer kept by Dr. Ginders. This shows that at $9 \mathrm{a} . \mathrm{m}$. on June 9 , the atmospheric pressure was $29^{\prime} 30$ (at about I 000 feet above the sea). It decreased and reached its lowest point of $29^{\circ} 00$ at 4 p.m. on the gth. It then began to rise. At midnight it was $29^{\circ} 08$, and at I a.m. on the Ioth-just before the eruption-it was $29^{\circ}$ IO. This pressure was maintained all through the principal part of the eruption, after which the glass began to rise again, reaching $29^{.25}$ at noon on the roth. The curve, elsewhere smooth and even, shows from 3.30 a.m. to 6 a.m. a number of small oscillations which treble its thickness. None of these oscillations are recorded before and none after 6 a.m. on the 9 th, except a single one at 5 p.m. on Friday, the IIth. These oscillations are attributed to earthquakes, but, whatever may have been their cause, they certainly mark the outburst of Rotomahana and the crisis of the eruption.

Another barometer at Ohinemutu, belonging to $\mathrm{Mr}$. Edwards, of the Native Lands Court, read as follows :-

$$
\begin{aligned}
& \text { June 9, Io a.m...............29. } 30 \text { inches } \\
& \text { 4.30 p.m. ...........29.00 , } \\
& \text { ", 10, I.55 a.m. ............29.20, }
\end{aligned}
$$

The following is the rainfall at Rotorua :-

$$
\begin{gathered}
\text { June } 4 \ldots \ldots \ldots \ldots \ldots \ldots \ldots \ldots \ldots \ldots \ldots \ldots \ldots \ldots \ldots \ldots \ldots \ldots \ldots \\
, y
\end{gathered}
$$


There was no rain at Rotorua between the $5^{\text {th }}$ and the eruption, but it rained on the $9^{\text {th }}$ at Wairoa and at Ateamuri, on the Waikato.

At Rotorua the slight mud-shower fell in directions from south-east to south-west, but most from the southeast, as ascertained by an examination of the telegraph poles. At Taheke, on Lake Rotoiti, the mud must have fallen with a south-south-east wind. At Galatea, eighteen miles east-south-east from Rotomahana, no mud fell ; but the scoria was thicker on the north-west than on the south-east side of the houses: evidently no strong wind was blowing.

The night of the gth was calm and fine. During the earlier portion of the eruption there was a slight southwesterly wind at Wairoa, which increased to a strong gale at 3 a.m. At Rotorua there was a slight south-easterly wind up to 4 a.m., when the south-westerly gale reached there from Wairoa. At Taheke, on Lake Rotoiti, the wind changed to south-west at 9 a.m, but there was no gale. At Napier a southerly gale commenced at 4 a.m.; at Gisborne, in Poverty Bay, a south-westerly gale was blowing; at Waiapu a strong north-westerly wind was blowing from $3.15 \mathrm{a} . \mathrm{m}$. to $4.30 \mathrm{a} . \mathrm{m}$., when it changed to the south-west. At the East Cape there was a strong southerly gale. It appears therefore that the south-westerly gale at Wairoa had no direct connection with the eruption, for it commenced about the same time all over the east coast from Napier to the East Cape.

I was surprised to find that the eruption had caused no great atmospheric disturbance, except in its immediate neighbourhood, and that there was no evidence at all of any indrawing currents. The reason for this, no doubt, is that the area over the openings which was violently disturbed is small, so that equilibrium was restored at very short distances around. For this reason a volcanic eruption has none of the effects of a cyclone. The eruption was, as usual, the cause of much electrical disturbance, but this did not affect the weather. F. W. HUTTuN

\section{A FEW OF OUR WEATHER TERMS}

$A$ RECENT skirmish in the Times, on certain words in common use among English meteorologists, and prevalent in our weather reports, suggests that a little overhauling of these and similar terms may be from time to time desirable. In a branch of knowledge which, simultaneously with its growth, becomes more and more popular, new terms expressive of new ideas should not only be accurately descriptive of facts, but should be adapted to popular imagination.

If we cannot have such terms as "helix" and "anthelix," the Meteorological Department cannot be on safer ground than in their adoption of the terms "cyclone" and "cyclonic," "anticyclone" and "anticyclonic"; these words being precisely antithetical, and expressive of phenomena which are the opposites of each other in almost all their characteristics. To both of these words, however, objections have been raised, and these objections have been somewhat inconsistently based on different reasons. The word cyclone has been objected to because it terrifies our women; but its equivalent, "revolver," would produce at least as alarming an effect. They would soon, however, get accustomed to the use of either. The most unscientific people will quickly understand that when the laws which govern a particular kind of atmospheric circulation have once been proved to be identical, whether that circulation be violent, moderate, or feeble, it becomes desirable to have a single term descriptive of such a circulation. Such nouns as "hurricane," "storm," \&c., can be employed, if we please, to denote that the disturbance is of a violent or severe character; while we have plenty of adjectives, strong or mild, to be employed at discretion. Perhaps this will be still more fully realised when the public understands that, in any particular instance, the circulat. ing winds may vary between the most violent and the lightest during the progress of the disturbance. As Mr. Abercromby clearly states it: "The same cyclone may develop the energy of a hurricane soon after its birth in the West Indies, and, after a long and stormy life in its passage across the Atlantic, die surrounded by gentle summer winds on the rocky coasts of Norway." The original use of the term "cyclone" was almost limited to the phenomenon in its acutest stage; and, owing partly to this fact, meteorologists have been disposed to apply the expressions "cyclonic system" and "cyclonic disturbance," \&c., to the gentler instances or stages of this kind of circulation, rather than the word "cyclone" itself; but the latter word might now be used without hesitation, for it is most true that " a progressive science uses words provisionally to express provisional ideas, and as the ideas increase in clearness and precision " (and, we may add, in extension) "the word has to take on new meanings."

The term "anticyclone" has been recently objected to as possessing absolutely no significance, an objection which is not in itself worthy of discussion in these pages This objection is, however, probably founded on one of a more serious nature, viz. that anticyclones are merely interspaces between cyclones. Such interspaces do, of course, exist, and they occasionally travel on without undergoing any very rapid change of form in company with the cyclones. But the interspaces between circles or ovals are not circular or oval; and further (as is more important to observe, and as has long ago been shown to be true) the anticyclone proper has characteristics of its own which distinguish it from these interspaces: its movements are often slow, or it is stationary for a considerable period, while in both hemispheres it has the power of deflecting the course of the cyclones moving in its vicinity more or less towards the right, except in particular positions.

Now let us look at the word "depression" and the ideas associated with it. It would probably be an impossible as well as an undesirable task to get rid of this term altogether, but for this reason it becomes all the more necessary clearly to define its meaning. Originally it signifies a lowering of the surface of the barometric column due to a diminution of pressure on the surface of the mercury in the cistern. It is equally well employed to designate a "taking off" or diminution of atmospheric pressure. In any case, it might be employed to designate such a diminution of pressure as takes place during the lessening or the passing off of an anticyclone. But by common usage it has come to be practically equivalent to cyclone, the only difference being (I) that it naturally refers to the diminution of pressure within the cyclone, and not the circulating winds, and (2) that it can be usefully applied to areas diverging considerably from the circular form. The ease with which the idea of a saucershaped hollow in the ocean of atmosphere is entertained, and the associations of the word "gradient" (a word valuable, suggestive, but figurative-a word for which I can find no substitute, unless it be a coined one), have certainly led to some misconceptions. Over the front or ascensional part of a cyclone, atmospheric pressure is greater at the level of four, five, or six miles above the earth's surface than over surrounding regions at the same level. It would be well for our storm-warnings if more people were careful to observe the violent north-westerly upper-current prevailing immediately in front of, and over, the southerly winds which we feel when a cyclonic disturbance is coming upon us from west-south-west. The few who have noticed this cannot fail to be struck by the fact that at the level of the cirrus the pressure must increase with extreme rapidity at the same time that pressure is decreasing at the earth's surface. It is true that in the rear of the disturbance an extension of the great 